\title{
THE EFFECTIVENESS OF ONLINE TEACHER TRAININGS IN THE FIELD OF MEDIA EDUCATION
}

\begin{abstract}
Today, the field of education is considered to be one of the important links that educates and brings up not only students, but also raises many demands and problems in the field of teacher certification and training. Educational changes, in turn, provide for the revision of curricula and the introduction of various media tools that allow the current conditions to be implemented not only on existing but also on remote platforms. To conduct education on these platforms, teachers participate in and train in seminars, webinars and courses at various educational institutions. As a result, they can easily switch from one platform to another and integrate into the new classroom gauge. They are able to participate in these trainings and a number of educational programs through the online platform, which is wider and more numerous than in the present case. The online platform is rapidly stabilizing its position in the field of education, already recording its success and effectiveness.

Keywords: trainings, media tools face-to-face and online trainings, media education, COVID-19

\section{Introduction}

The situation in the world today has completely changed not only the nature and structure of the educational process in schools and other educational institutions, but also the teachers' completely different requirements to carry out the educational process online. In order to make the educational process more effective, teachers not only change their curricula and work style, but also change the materials and methods they use to fit the online platform. The latter, in turn, promotes the acquisition and application of many new knowledge and skills. There are various online programs and tools in the media field today to make online learning more effective.
\end{abstract}




\section{Method}

However, because of to the current situation in the world, online platform training has become more popular. Training is held everywhere, at any time in any place of the world. Online training can be organized in a short period of time and have gained more popularity because of their structure and degree of teacher participation (Tallent-Runnels et al., 2006). Online training doesn't need any effort to move from one place to another place, any kind of time, transport or payment to participate. Any teacher can participate from any part of the world at any time (Durgaryan A., 2020).

Online learning, in turn, requires teachers to master the use of media tools and their proper use (Topouzyan A. O., Gyulamiryan J. H., Asatryan S. M., Poghosyan L. M., 2020). The online platform gave teachers the opportunity to participate in trainings organized by different countries and gain new knowledge and skills. Online training is invaluable for teachers, allowing them to share their experience and knowledge through an online platform. With the help of the latest technologies, teachers are able to conduct their lessons online and communicate with their students at the same time remotely (Rienties et al., 2013)

The effectiveness of online teacher training depends on a number of factors, including:

- Personal interest

- Introduction of theoretical approaches to educational institutions through online media tools.

- Practice that allows teachers to use a variety of media tools to make their lessons richer and more meaningful.

- Online training offers effective ways for teachers. A number of studies show that online training has become more widespread, providing flexibility and efficiency through which teachers can access new learning platforms. At the same time, they get the opportunity to participate in trainings conducted by the world's leading educators and teachers through an online learning method.

- Improving skills and knowledge through the many online media tools, workshops, workshops, etc.

- Online training gives teachers the opportunity to practice their CPD and gain more in-depth knowledge and skills in their subject area.

\section{Research}

The research was conducted in Hrazdan Basic School No. 11 after William Saroyan. 
About 80 primary and secondary school teachers took part in the survey. One of the main tasks during the research was to find out the specifics of the training of teachers who participated in the online platform, the ways and results of their organization. The results of the research were analyzed. The results were presented in the form of diagrams. The aim of the research was to identify the specifics of the effectiveness of teacher training online and to make the process more targeted and effective. During the research, observations and interviews were conducted among teachers who participated and did not participate in online trainings. Most of the teachers who participated in the online training expressed their positive opinion about its effectiveness:

Figure 1

Index of teacher participation in online training

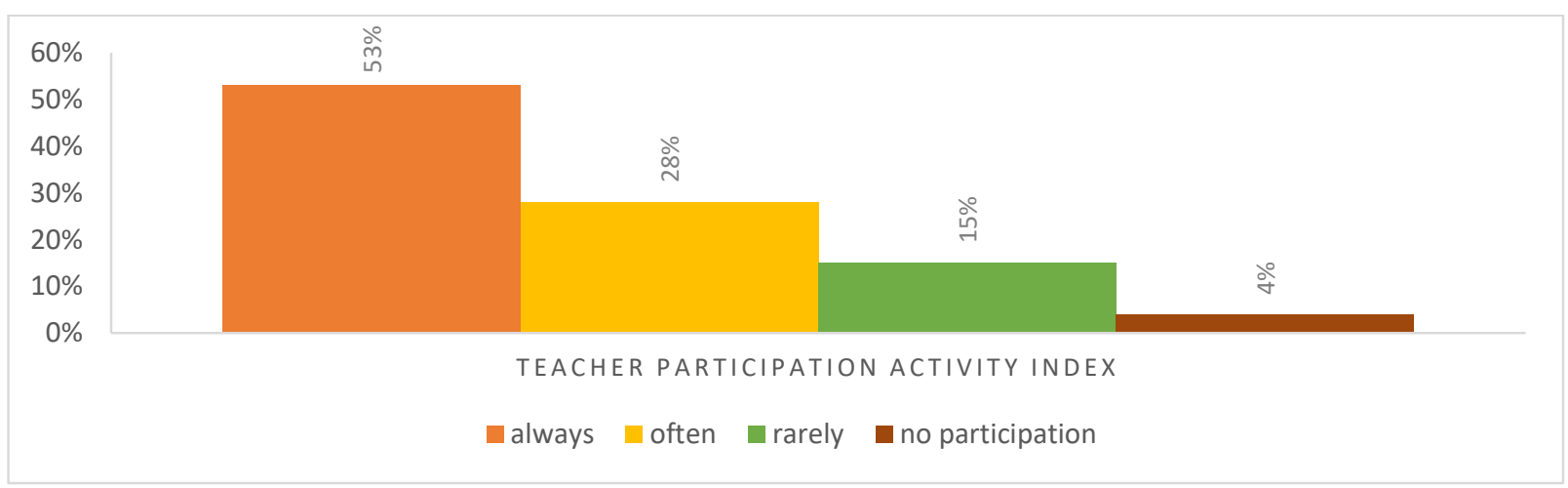

The results of surveys on the effectiveness of teacher training on the online platform showed that they are based on a number of factors, including technical factors, ways and purposes of organizing training, tasks, selection and use of necessary and appropriate media tools. The survey results are presented in the chart below.

Figure2

Teachers' attitude towards online training

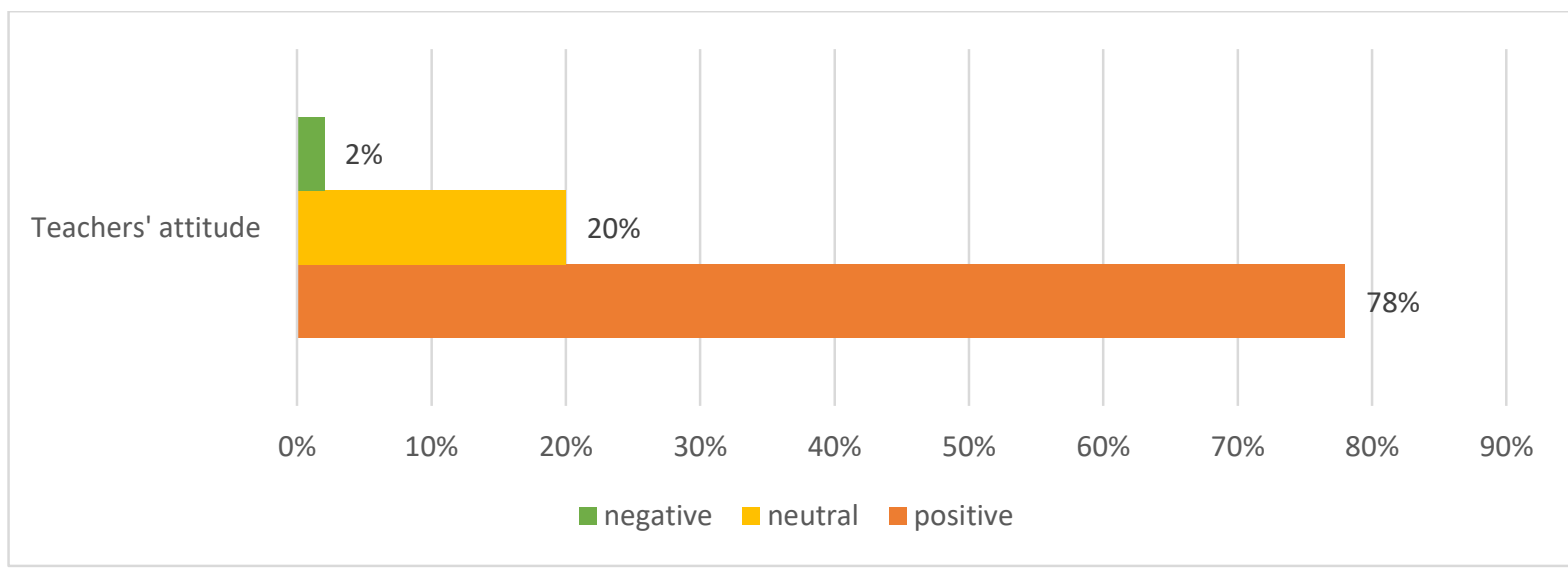

As shown in the chart, the effectiveness of teacher training on the online platform through media tools has high results and indicators that prove its effectiveness and 
accessibility.

Based on the results obtained at the end of the study, comparisons were made before the current epidemic conditions and before them, an analysis of the results of online teacher training, which we presented through a chart.

Figure 3

\section{Comparison of online training over a period of time}

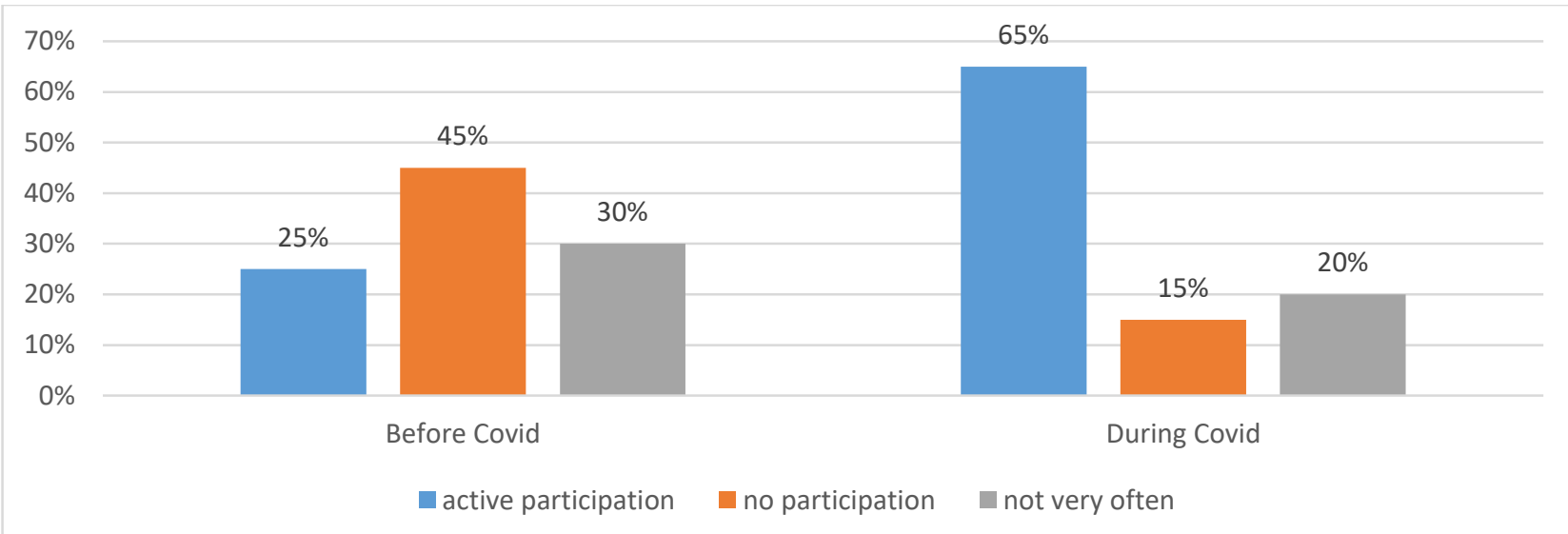

The records in Figure 3 show different index before and during the pandemic situations.. Teachers who before the pandemic of the world did not even think about participating in online teacher training now prefer online platform training. They explain this fact by not being aware of online training before, considering its effectiveness absurd. Now, despite the fact that many training centers are already organizing existing trainings, teachers still find it difficult to attend the existing trainings, preferring online trainings. The effectiveness of online training is evidenced by the versatile use of media tools and its effectiveness, which allows many professionals to be trained and use media tools as modern technologies to make the lesson more effective and diverse, in line with modern requirements.

\section{Conclusion}

As a result of surveys and reviews to ensure the effectiveness of online teacher training, we have been able to record the need for work to increase the effectiveness of online training and have an idea of their need and the situation created by the pandemic in today's world. The use of many media tools allows teachers not only to be trained through these tools, but also to be able to use them in the future in their work and learning process.

Through the research, we were able to study not only the effectiveness of teacher training through an online platform, but also to identify the factors that ensure effectiveness. Online training is effective and relevant, as evidenced by a number of 
factors, such as:

- Correspondence of appropriate conditions of time and place.

- Wide range of training not only within the country but all over the world.

- Gaining new experience and knowledge by the world's leading professionals.

- Ensuring the diverse diversity of teacher training, from seminars and webinars to specially focused training, etc.

If we analyze the disadvantages of online training, we can mention the disadvantages can be corrected or discarded in order to have beneficial and effective trainings. To sum up, we can say that training is a source that forces teachers to be more skillful and experienced in the path of their career promotion.

Each of these factors has a unique effect on the effectiveness of teacher training activities through the online platform and its proper organization. The media tools used to solve the problems and difficulties encountered on the online platform and the factors that ensure the effectiveness of the training process allow the process to be organized in accordance with the most appropriate and up-to-date educational requirements.

\section{References}

Durgaryan A. (2020). Modern issues of teacher training on the virtual platform. Meta Magazine, 5(2), 6-10.

Rienties, B., Brouwer, N., \& Lygo-Baker, S. (2013). The effects of online professional development on higher education teachers' beliefs and intentions towards learning facilitation and technology. Teaching and Teacher Education, 29, 122-131. https://doi.org/10.1016/j.tate.2012.09.002

Tallent-Runnels, M. K., Thomas, J. A., Lan, W. Y., Cooper, S., Ahern, T. C., Shaw, S. M., \& Liu, X. (2006). Teaching Courses Online: A Review of the Research. Review of Educational Research, 76(1), 93-135. https://doi.org/10.3102/00346543076001093

Topouzyan A. O., Gyulamiryan J. H., Asatryan S. M., Poghosyan L. M. (2020). Mediatexnologianery' tarrakan dproci mankavarjhakan gorcyntacoum (Media technologies in the elementary school pedagogical process). Yerevan. Gitutyun, 168. 